\title{
Risk factors for proctectomy in consecutive Crohn's colitis surgical patients in a reference colorectal centre
}

\author{
Gisele Aaltonen $^{1}$ (D) $\cdot$ Monika Carpelan-Holmström ${ }^{1} \cdot$ Ilona Keränen $^{1} \cdot$ Anna Lepistö ${ }^{1}$
}

Accepted: 19 June 2019 / Published online: 28 June 2019

(C) The Author(s) 2019

\begin{abstract}
Purpose Crohn's colitis carries a risk for permanent stoma with extirpation of the rectum. We aimed to estimate the proctectomy rate and identify risk factors for proctectomy in patients with Crohn's colitis.

Methods For this study, we retrospectively reviewed data from consecutive patients with Crohn's disease (CD) affecting the colon or anorectal region undergoing bowel resection in a reference colorectal centre between 2006 and 2016. The cumulative risk for proctectomy was calculated using the Kaplan-Meier curve. We used univariate and multivariate logistic regression analyses to determine independent risk factors for proctectomy. Outcomes after proctectomy concerning reoperation frequency and perineal wound healing are also described.

Results In total, this study included 125 patients. Proctectomy was performed in 36 patients (28.8\%), of whom 14 patients (38.9\%) experienced perineal wound healing problems. The rates of proctectomy were $5.6 \%$ and $32.0 \% 10$ and 20 years after CD diagnosis, respectively. Female gender (odds ratio (OR) 3.375, 95\% confidence interval (CI) 1.304-8.733, $P=0.012$ ), disease duration (OR 1.067, 95\% CI 1.011-1.126, $P=0.018$ ) and history of perianal disease (OR 3.160, 95\% CI 1.215-8.219, $P=0.018)$ were independent risk factors for a proctectomy procedure, whereas thiopurine medication $(\mathrm{OR} 0.170,95 \% \mathrm{CI} 0.060-0.486, P=$ 0.001 ) was an independent protective factor for proctectomy.

Conclusions The duration of Crohn's disease, female gender and a history of perianal disease were significant risk factors for a proctectomy procedure. Future research should examine whether immunosuppressive and biological medications reduce the risk for proctectomy.
\end{abstract}

Keywords Crohn's colitis · Crohn's disease $\cdot$ Definitive stoma $\cdot$ Proctectomy $\cdot$ Risk factors

\section{Introduction}

According to population-based studies, the incidence of Crohn's colitis has increased in recent decades $[1,2]$. It is estimated that more than $60 \%$ of Crohn's disease (CD) patients have colonic involvement. Isolated Crohn's colitis is found in $20 \%$ of patients suffering from $\mathrm{CD}$, but ileocolonic involvement is more common [3]. CD of the colon or anorectal region is associated with a risk for definitive stoma requiring extirpation of the rectum. Many patients affected by this type of $\mathrm{CD}$ fear permanent stoma. Temporary stoma

Gisele Aaltonen

gisele.aaltonen@helsinki.fi

1 Department of Colorectal Surgery, Helsinki University Hospital, P.O. Box 340, 00029 HUS, Helsinki, Finland formation may be used to control disease while allowing for the recovery of the bowel distal to the covering stoma. However, a recent meta-analysis has shown that only $34 \%$ of $\mathrm{CD}$ patients with temporary stoma will ever have their stoma closed and only $16 \%$ of these patients will improve without undergoing a new stoma construction [4]. Furthermore, previous studies reported proctectomy rates of $20 \%$ in Crohn's colitis patients $[5,6]$.

One randomized controlled trial described a diminished need for perianal disease surgery in patients treated with thiopurine medication [7]. In addition, biological medications appear to improve perianal disease [8-10]. However, previous studies did not specifically evaluate the effect of CD medications in preventing proctectomy and further investigations are needed.

Construction of end colostomy with preservation of part of the large bowel increased postoperative $\mathrm{CD}$ recurrence in Crohn's colitis patients according to previous studies [11, 12]. 
Concomitant terminal ileum disease was also described as a risk factor for postoperative CD recurrence in Crohn's colitis patients $[13,14]$.

Our study aimed to determine the proctectomy rate and identify the risk factors for proctectomy in surgical Crohn's colitis patients. Furthermore, we evaluated the frequency of reoperations and delayed perineal wound healing after proctectomy.

\section{Material and methods}

Clinical records from all patients with colonic or anorectal CD undergoing bowel resection in a reference colorectal centre between 2006 and 2016 were retrospectively reviewed for this study. We excluded patients with disease limited to the small bowel or terminal ileum without involvement of the colon or anorectal region. We collected data on patient age, gender, date of CD diagnosis, history of perianal disease and terminal ileum disease, as well as the use of corticosteroids, thiopurine and biological medications. As preoperative medication, we considered the medication in use for the last 6 months before surgery. The index operation was either proctectomy or other bowel resection in patients not referred for proctectomy during the study period. Proctectomy date, indication, approach and the frequency of perineal complications and reoperations during follow-up were also recorded. Reoperation was defined as the need for a new bowel resection due to recurrent disease. CD duration was calculated from the date of diagnosis until the date of the index operation.

The Kaplan-Meier curve was used to calculate the cumulative risk for proctectomy from CD diagnosis until the end of follow-up. Risk factors for proctectomy were identified using univariate and multivariate logistic regression analyses. Univariate variables with $P<0.05$, which we considered statistically significant, were included in the multivariate analyses. The Fisher's exact test was used to compare subgroups in patients undergoing reoperation after proctectomy.

\section{Results}

\section{All patients}

A total of 125 patients with colonic or anorectal CD underwent bowel resection between 2006 and 2016, all of whom we included in our study. Table 1 shows the patient characteristics, while the types of index operations appear in Table 2.

At least one previous CD operation was performed on 61 patients $(48.8 \%) ; 32$ patients $(25.6 \%)$ underwent two or more previous CD operations. Previous CD operations consisted of the following: 15 ileocaecal resections, 12 small bowel resections, 30 segmental colon resections, 7 colectomies with ileorectal anastomosis, 4 colectomies with ileostomy and multiple operations for perianal abscesses and fistulas.

Table 1 Patient descriptive data

\begin{tabular}{llll}
\hline Patient characteristics & All cases & Proctectomy & \\
\cline { 3 - 4 } & & No & Yes \\
\hline Number of patients & $125(100 \%)$ & $89(71.2 \%)$ & $36(28.8 \%)$ \\
Median age at index operation & $39.0(14.8-74.1)$ & $34.0(14.8-74.1)$ & $40.5(22.9-69.4)$ \\
Median age at diagnosis & $21.8(3.1-69.9)$ & $22.2(5.2-69.9)$ & $20.5(3.1-53.3)$ \\
Gender & & & \\
Male & $66(52.8 \%)$ & $54(60.7 \%)$ & $12(33.3 \%)$ \\
Female & $59(47.2 \%)$ & $35(39.3 \%)$ & $24(66.7 \%)$ \\
Median duration of CD & $12.0(0-36.8)$ & $9.1(0-36.8)$ & $16.9(5.0-32.3)$ \\
Median time from index surgery & $4.4(0-10.7)$ & $4.4(0.3-10.7)$ & $4.6(0-10.5)$ \\
Median time from diagnosis & $16.7(0.5-39.8)$ & $14.8(0.5-39.8)$ & $19.0(5.5-38.0)$ \\
Preoperative biological medication & $43(34.4 \%)$ & $34(38.2 \%)$ & $9(25.0 \%)$ \\
Preoperative corticosteroid medication & $43(34.4 \%)$ & $35(39.3 \%)$ & $8(22.2 \%)$ \\
Preoperative thiopurine medication & $98(78.4 \%)$ & $77(86.5 \%)$ & $21(58.3 \%)$ \\
History of perianal CD & $63(50.4 \%)$ & $37(41.6 \%)$ & $26(72.2 \%)$ \\
History of terminal ileum CD & $89(71.2 \%)$ & $72(80.9 \%)$ & $17(47.2 \%)$ \\
\hline
\end{tabular}

$C D$ Crohn's disease; values are in years (range) for continuous variables and frequencies (proportion) for categorical variables 
Table 2 Types of index operations

\begin{tabular}{ll}
\hline Operation & $\begin{array}{l}\text { Total } \\
(n=125)\end{array}$ \\
\hline Small bowel resection & $5(4.0 \%)$ \\
Right colon resection & $59(47.2 \%)$ \\
Left colon resection & $15(12.0 \%)$ \\
Segmental or subtotal colon resection & $7(5.6 \%)$ \\
Colectomy & $3(2.4 \%)$ \\
Proctocolectomy & $5(4.0 \%)$ \\
Proctectomy & $31(24.8 \%)$ \\
\hline
\end{tabular}

The cumulative rates of proctectomy were $5.6 \%$ and $32.0 \%$ 10 and 20 years from CD diagnosis, respectively (Fig. 1).

Table 3 shows the risk factors for proctectomy. In the multivariate analysis, CD duration, female gender and perianal CD were independent risk factors for proctectomy. The use of thiopurines was an independent protective factor for proctectomy.

\section{Proctectomy patients}

A proctectomy was performed on 36 patients $(28.8 \%)$ at a median of 16.9 years (5.0-32.2 years) from CD diagnosis. The indications for proctectomy are listed in Table 4. Proctectomy was performed by the perineal approach in 3 patients $(8.3 \%)$, the abdominal approach in 5 patients $(13.9 \%)$ and the combined abdominoperineal approach in 28 patients $(77.8 \%)$.

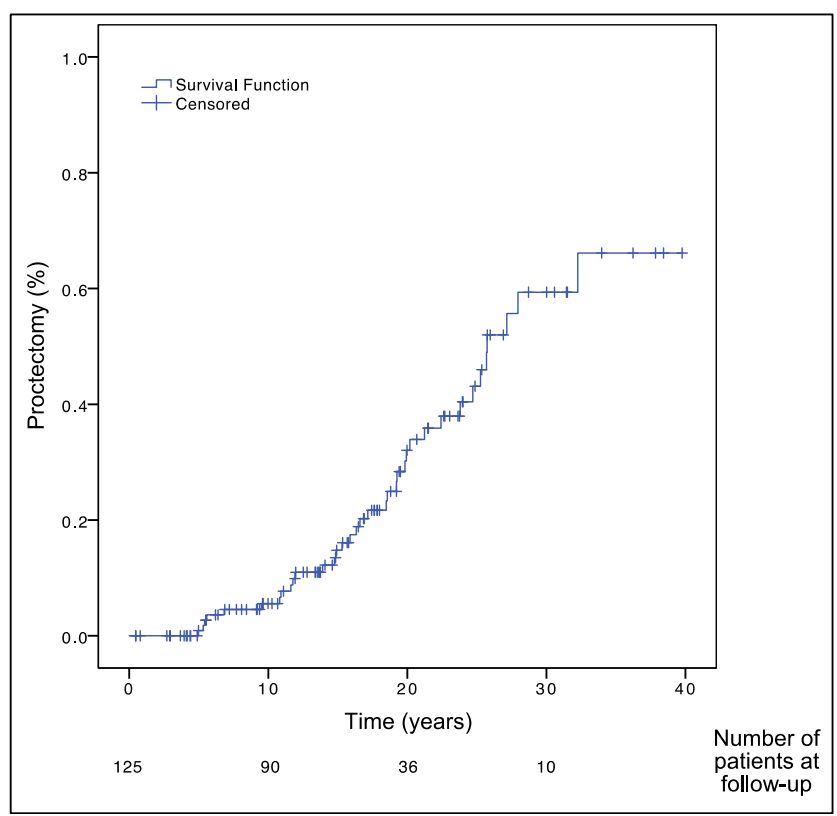

Fig. 1 Cumulative probability of proctectomy in surgical Crohn's colitis patients
Altogether, 14 patients $(38.9 \%)$ experienced problems with perineal wound healing. Furthermore, two patients (5.6\%) who underwent proctectomy through the abdominal approach only, subsequently required reoperation for the removal of the anus.

After proctectomy, 8 patients $(22.2 \%)$ required at least 1 reoperation due to recurrent $\mathrm{CD}$. Reoperations consisted of 7 ileal resections performed on 5 patients and 6 colon resections performed on 5 patients.

The reoperation frequency in patients with a history of terminal ileum disease was $29.4 \%$ (5 of 17 patients); the frequency in patients without terminal ileum disease was $15.8 \%$ (3 of 19 patients, $P=0.28$ ). The reoperation frequency involving only ileal resections was $23.5 \%$ (4 of 17 patients) in patients with a history of terminal ileum disease and $5.3 \%$ (1 of 19 patients) in patients with no such history $(P=0.14)$.

The reoperation frequency in patients who underwent proctectomy with end colostomy was $31.6 \%$ (6 of 19 patients) and $11.8 \%$ ( 2 of 17 patients) in patients who underwent proctectomy with end ileostomy $(P=0.15)$.

In the proctectomy group, 20 patients $(55.6 \%)$ had an end ileostomy, 9 patients $(25.0 \%)$ had an end transversostomy and 7 patients (19.4\%) had an end sigmoideostomy at the end of the follow-up.

\section{Discussion}

In our cohort of Crohn's colitis patients who underwent bowel resection, $28.8 \%$ had a proctectomy performed during followup. This is comparable with previous studies that described a 19.2 to $25.4 \%$ proctectomy rate after colectomy $[5,6,15]$. Our group of patients is more heterogeneous and included patients referred for different bowel resections, but all patients had colonic or anorectal CD.

The proctectomy rate in our study group calculated with the Kaplan-Meier curve was only 5.6\% 10 years from CD diagnosis. This low rate can be explained by the fact that some of our patients may not have had colonic involvement at the beginning of disease. Proctectomy risk increases over time, with rates as high as $32 \% 20$ years after $\mathrm{CD}$ diagnosis. By contrast, this high rate must be interpreted with caution, since our study included only Crohn's colitis patients who underwent bowel resection. That is, this patient group may be at higher risk for proctectomy. Previous population-based studies have estimated the rate of definitive stoma as around 14\% 20 years after CD diagnosis [16, 17].

We found that the presence of perianal disease is a risk factor for proctectomy, a result also observed by others [16, 18, 19]. In comparison, O'Riordan et al. [6] did not find perianal disease to be a risk factor for proctectomy in their study that included patients who underwent colectomy with ileorectal anastomosis. According to their 
Table 3 Logistic regression analyses of risk factors for proctectomy in surgical Crohn's colitis patients

\begin{tabular}{|c|c|c|c|c|}
\hline & \multicolumn{2}{|l|}{ Univariate analysis } & \multicolumn{2}{|l|}{ Multivariate analysis } \\
\hline & $\begin{array}{l}\text { Unadjusted } \\
\text { OR }(95 \% \mathrm{CI})\end{array}$ & $P$ value & $\begin{array}{l}\text { Adjusted } \\
\text { OR }(95 \% \mathrm{CI})\end{array}$ & $P$ value \\
\hline Age at diagnosis & $0.984(0.954-1.015)$ & 0.312 & - & - \\
\hline Female gender & $3.086(1.369-6.958)$ & 0.007 & $3.375(1.304-8.733)$ & 0.012 \\
\hline Duration of CD & $1.084(1.034-1.136)$ & 0.001 & $1.067(1.011-1.126)$ & 0.018 \\
\hline History of perianal CD & $3.654(1.574-8.484)$ & 0.003 & $3.160(1.215-8.219)$ & 0.018 \\
\hline Biological medication & $0.539(0.227-1.283)$ & 0.163 & - & - \\
\hline Corticosteroid medication & $0.441(0.180-1.077)$ & 0.072 & - & - \\
\hline Thiopurine medication & $0.218(0.089-0.536)$ & 0.001 & $0.170(0.060-0.486)$ & 0.001 \\
\hline
\end{tabular}

$O R$ odds ratio; $C I$ confidence interval; $C D$ Crohn's disease; $n=125$

study, smoking was the only independent risk factor for proctectomy. We could not analyse the influence of smoking in our study, since smoking data at the time of proctectomy was not available.

The risk of perianal disease development in CD patients has been estimated to be as high as $42.7 \% 20$ years after diagnosis [20]. According to that population-based study, perianal disease not only can manifest many years before $\mathrm{CD}$ is diagnosed, but can also occur three decades after $\mathrm{CD}$ diagnosis. Furthermore, perianal disease is known to be more common in patients with Crohn's colitis [11,21,22].

In our study, female gender was an independent risk factor for proctectomy, a finding consistent with one previous study that concluded that female gender is a risk factor for reoperation following segmental colonic resection for CD [19]. The reason for this remains unclear, but might be due to different attitudes to perianal disease and to permanent stoma between genders.

In addition, the use of thiopurines was an independent protective factor for proctectomy in our study. However, this result should be interpreted with caution since this was a retrospective study. It is possible that patients receiving thiopurines had less aggressive $\mathrm{CD}$ and, therefore, did not require proctectomy during follow-up. A metaanalysis of 5 randomized controlled trials showed a $54 \%$ improvement of perianal disease in $\mathrm{CD}$ patients after thiopurine treatment in contrast to a $21 \%$ improvement

Table 4 Indications for proctectomy in the control group [23]. More recently, one randomized controlled trial showed that thiopurines reduced the need for surgery in perianal disease patients [7].

Biological medications are effective in the treatment of perianal disease [8-10]. Combined anti-tumour necrosis factor-alpha and thiopurine therapy represents the treatment of choice in refractory perianal disease [24]. These studies detected an improvement in perianal disease, but did not specifically evaluate the effect of biological medications in preventing proctectomy.

Coscia et al. [15] compared the risk for permanent stoma surgery before and after the biological medication era. They concluded that the risk for permanent stoma surgery was significantly reduced after the introduction of biological medications. By contrast, a meta-analysis of 556 patients on the requirement for stoma surgery in CD patients concluded that biological medications did not decrease proctectomy rates and only the absence of rectal involvement was significant in the maintenance of bowel continuity [4].

Previous studies have detected a high recurrence rate in Crohn's colitis in patients with a history of concomitant terminal ileal disease $[13,14]$. In our study, these patients also had more reoperations. However, the difference was not significant perhaps due to the small number of patients in the subgroups. Previous studies have also described an increased recurrence rate after end colostomy compared with end ileostomy in Crohn's colitis patients $[11,12]$. The same tendency was observed in our study, although our subgroup analysis did not achieve statistical significance. From a clinical point of view, we would expect disease recurrence in the remaining colon after colostomy. However, it is usually beneficial for the patient to retain some colon as long as possible, even if further operations are needed.

Perineal wound healing problems after proctectomy in $\mathrm{CD}$ have been previously described $[25,26]$. Yamamoto et al. [25] detected persistent perineal sinuses in $23 \%$ of 
patients who had proctocolectomy. In our study, $38.9 \%$ of the patients who underwent proctectomy experienced delayed perineal wound healing. Furthermore, previous perianal $\mathrm{CD}$ has been described as a risk factor for perineal wound healing difficulties after proctectomy [26].

Our study has some limitations due to its retrospective design, possibly causing selection bias. We emphasize that our results may not reflect Crohn's colitis population as a whole, since we only included patients undergoing bowel resection in this study. Patients who did not have proctectomy had a shorter follow-up time from diagnosis than patients with proctectomy. As previously mentioned, patients treated with thiopurines may have had less aggressive $\mathrm{CD}$ than those treated with biological medications.

In conclusion, $\mathrm{CD}$ duration, female gender and the presence of perianal $\mathrm{CD}$ are significant independent risk factors for proctectomy in Crohn's colitis patients undergoing bowel resection. Further research is necessary to determine if immunosuppressive and biological medications can reduce proctectomy rates in $\mathrm{CD}$ patients.

Funding Information Open access funding provided by University of Helsinki including Helsinki University Central Hospital.

\section{Compliance with ethical standards}

All procedures performed in this study were in accordance with the ethical standards of the institutional and national research committee and with the 1964 Helsinki Declaration and comparable ethical standards. For this type of study, formal consent was not required.

Conflict of interest The authors declare that they have no conflicts of interest.

Open Access This article is distributed under the terms of the Creative Commons Attribution 4.0 International License (http:// creativecommons.org/licenses/by/4.0/), which permits unrestricted use, distribution, and reproduction in any medium, provided you give appropriate credit to the original author(s) and the source, provide a link to the Creative Commons license, and indicate if changes were made.

\section{References}

1. Lapidus A, Bernell O, Hellers G, Lofberg R (1998) Clinical course of colorectal Crohn's disease: a 35-year follow-up study of 507 patients. Gastroenterology 114:1151-1160

2. Andersson P, Olaison G, Hallbook O, Sjodahl R (2002) Segmental resection or subtotal colectomy in Crohn's colitis? Dis Colon Rectum 45:47-53

3. Mills S, Stamos MJ (2007) Colonic Crohn's disease. Clin Colon Rectal Surg 20:309-313

4. Singh S, Ding NS, Mathis KL, Dulai PS, Farrell AM, Pemberton JH, Hart AL, Sandborn WJ, Loftus EV Jr (2015) Systematic review with meta-analysis: faecal diversion for management of perianal Crohn's disease. Aliment Pharmacol Ther 42:783-792
5. Longo WE, Oakley JR, Lavery IC, Church JM, Fazio VW (1992) Outcome of ileorectal anastomosis for Crohn's colitis. Dis Colon Rectum 35:1066-1071

6. O'Riordan JM, O'Connor BI, Huang H, Victor JC, Gryfe R, MacRae HM, Cohen Z, McLeod RS (2011) Long-term outcome of colectomy and ileorectal anastomosis for Crohn's colitis. Dis Colon Rectum 54:1347-1354

7. Cosnes J, Bourrier A, Laharie D, Nahon S, Bouhnik Y, Carbonnel F, Allez M, Dupas JL, Reimund JM, Savoye G, Jouet P, Moreau J, Mary JY, Colombel JF, Groupe d'Etude Therapeutique des Affections Inflammatoires du Tube D (2013) Early administration of azathioprine vs conventional management of Crohn's disease: a randomized controlled trial. Gastroenterology 145:758-765 e752; quiz e714-755

8. Present DH, Rutgeerts P, Targan S, Hanauer SB, Mayer L, van Hogezand RA, Podolsky DK, Sands BE, Braakman T, DeWoody KL, Schaible TF, van Deventer SJ (1999) Infliximab for the treatment of fistulas in patients with Crohn's disease. N Engl J Med 340: 1398-1405

9. Sands BE, Anderson FH, Bernstein CN, Chey WY, Feagan BG, Fedorak RN, Kamm MA, Korzenik JR, Lashner BA, Onken JE, Rachmilewitz D, Rutgeerts P, Wild G, Wolf DC, Marsters PA, Travers SB, Blank MA, van Deventer SJ (2004) Infliximab maintenance therapy for fistulizing Crohn's disease. N Engl J Med 350: 876-885

10. Lichtiger S, Binion DG, Wolf DC, Present DH, Bensimon AG, Wu E, Yu AP, Cardoso AT, Chao J, Mulani PM, Lomax KG, Kent JD (2010) The CHOICE trial: adalimumab demonstrates safety, fistula healing, improved quality of life and increased work productivity in patients with Crohn's disease who failed prior infliximab therapy. Aliment Pharmacol Ther 32:1228-1239

11. de Buck van Overstraeten A, Wolthuis AM, Vermeire S, Van Assche G, Rutgeerts P, Penninckx F, D'Hoore A (2013) Intersphincteric proctectomy with end-colostomy for anorectal Crohn's disease results in early and severe proximal colonic recurrence. J Crohns Colitis 7:e227-e231

12. Koriche D, Gower-Rousseau C, Chater C, Duhamel A, Salleron J, Tavernier N, Colombel JF, Pariente B, Cortot A, Zerbib P (2017) Post-operative recurrence of Crohn's disease after definitive stoma: an underestimated risk. Int J Colorectal Dis 32:453-458

13. Lock MR, Fazio VW, Farmer RG, Jagelman DG, Lavery IC, Weakley FL (1981) Proximal recurrence and the fate of the rectum following excisional surgery for Crohn's disease of the large bowel. Ann Surg 194:754-760

14. Cattan P, Bonhomme N, Panis Y, Lemann M, Coffin B, Bouhnik Y, Allez M, Sarfati E, Valleur P (2002) Fate of the rectum in patients undergoing total colectomy for Crohn's disease. Br J Surg 89:454 459

15. Coscia M, Gentilini L, Laureti S, Gionchetti P, Rizzello F, Campieri M, Calabrese C, Poggioli G (2013) Risk of permanent stoma in extensive Crohn's colitis: the impact of biological drugs. Colorectal Dis 15:1115-1122

16. Post S, Herfarth C, Schumacher H, Golling M, Schurmann G, Timmermanns G (1995) Experience with ileostomy and colostomy in Crohn's disease. Br J Surg 82:1629-1633

17. Etienney I, Bouhnik Y, Gendre JP, Lemann M, Cosnes J, Matuchansky C, Beaugerie L, Modigliani R, Rambaud JC (2004) Crohn's disease over 20 years after diagnosis in a referral population. Gastroenterol Clin Biol 28:1233-1239

18. Kiran RP, Nisar PJ, Church JM, Fazio VW (2011) The role of primary surgical procedure in maintaining intestinal continuity for patients with Crohn's colitis. Ann Surg 253:1130-1135

19. Polle SW, Slors JF, Weverling GJ, Gouma DJ, Hommes DW, Bemelman WA (2005) Recurrence after segmental resection for colonic Crohn's disease. Br J Surg 92:1143-1149 
20. Eglinton TW, Barclay ML, Gearry RB, Frizelle FA (2012) The spectrum of perianal Crohn's disease in a population-based cohort. Dis Colon Rectum 55:773-777

21. Schwartz DA, Loftus EV Jr, Tremaine WJ, Panaccione R, Harmsen WS, Zinsmeister AR, Sandborn WJ (2002) The natural history of fistulizing Crohn's disease in Olmsted County, Minnesota. Gastroenterology 122:875-880

22. Lewis RT, Bleier JI (2013) Surgical treatment of anorectal crohn disease. Clin Colon Rectal Surg 26:90-99

23. Pearson DC, May GR, Fick GH, Sutherland LR (1995) Azathioprine and 6-mercaptopurine in Crohn disease. A meta-analysis. Ann Intern Med 123:132-142

24. Colombel JF, Sandborn WJ, Reinisch W, Mantzaris GJ, Kornbluth A, Rachmilewitz D, Lichtiger S, D'Haens G, Diamond RH, Broussard DL, Tang KL, van der Woude CJ, Rutgeerts P, Group
SS (2010) Infliximab, azathioprine, or combination therapy for Crohn's disease. N Engl J Med 362:1383-1395

25. Yamamoto T, Keighley MR (2000) Fate of the rectum and ileal recurrence rates after total colectomy for Crohn's disease. World J Surg 24:125-129

26. Genua JC, Vivas DA (2007) Management of nonhealing perineal wounds. Clin Colon Rectal Surg 20:322-328

Publisher's note Springer Nature remains neutral with regard to jurisdictional claims in published maps and institutional affiliations. 